\section{Resistir a los violentos y tejer sociedad desde la fe: El Garzal (Colombia)*}

\author{
William Elvis Plata \\ Sergio Cáceres Mateus**
}

RECIBIDO: 13-05-15 - APROBADO: 06-07-15

Resumen: Rescata la memoria histórica de una comunidad cristiana evangélica que, ante los embates de la violencia, decide organizarse y resistir pacíficamente, fundamentada en su fe. A partir de ahí reflexiona sobre el rol que las iglesias y las organizaciones religiosas tienen y pueden tener en la superación del conflicto armado, en la generación de procesos de desarrollo y en la construcción de una cultura de paz y reconciliación.

Palabras Clave: Protestantismo, pentecostalismo, conflicto armado, paramilitarismo, resistencia a la opresión.

PARA CITAR ESTE ARTÍCULO:

Plata, William Elvis y Cáceres, Sergio. "Resistir a los violentos y tejer sociedad desde la fe: El Garzal (Colombia)". Theologica Xaveriana 180 (2015): 497-525. http://dx.doi.org/10.11144/javeriana. tx65-180.rvts

\section{To Resist to the Violent Forces and to Create Social Fabric from Faith: El Garzal (Colombia)}

Aвstract: This article rescues the historical memory of a Christian evangelical community that, because of its faith, decides to organize and to resist peacefully the attacks of violence. Considering this experience, the authors think about the role that churches and religious institutions have and could have to overcome the armed conflict, to create processes of development and to develop a culture of peace and reconciliation.

Key words: Protestantism, Pentecostalism, armed conflict, paramilitary forces, resistance to oppression.

Resistir aos violentos e tecer sociedade através da fé: El Garzal (Colômbia)

Resumo: Resgata a memória histórica de uma comunidade cristã evangélica, que diante dos embates da violência decide organizar-se e resistir pacificamente, fundamentada em sua fé. Partindo deste ponto, reflexiona sobre o papel que as igrejas e as organizaçóes religiosas têm e podem ter na superaçáo do conflito armado, na geração de processos de desenvolvimento e na construçáo de uma cultura de paz e reconciliação.

Palavras chave: Protestantismo, pentecostalismo, conflito armado, para-militarismo, resistência à opressão.

\footnotetext{
*Artículo de investigación, resultado parcial del proyecto "Memoria de resistencias desde la fe en el Magdalena Medio colombiano", realizado en 2013-2014 y financiado por el Centro Nacional de Memoria Histórica y la Universidad Industrial de Santander, Colombia (Cod. UIS 8247) Los autores agradecen al pastor Salvador Alcántara, a su esposa Nidia Alian y a toda la comunidad de El Garzal, por su disposición para contar su historia y apoyar este proyecto.

** William Elvis Plata: Doctor en Histoire, Art et Archéologie, Université de Namur - Académie Louvain. Profesor asociado, Escuela de Historia, Universidad Industrial de Santander, Bucaramanga. Correo electrónico: weplataq@uis.edu.co. Sergio Cáceres Mateus: Historiador, Universidad Industrial de Santander, Bucaramanga. Miembro del grupo de investigación "Sagrado y profano". Correo electrónico: scaceres8616@yahoo.com
} 


\section{Introducción}

26 de octubre de 2003: los paramilitares del bloque Central Bolívar, presentes desde hace cinco años en el sur del departamento de Bolívar, en el Magdalena Medio colombiano, llegaron a la población de Simití. Uno de estos grupos estaba comandado por alias Don Pedro, cuyo nombre verdadero era Manuel Enrique Barreto, antiguo presunto narcotraficante, quien ya había hecho presencia en la región en los años 80 .

Cundió el rumor de que venía a tomarse las que considera "sus tierras" y expulsar a las gentes que las habitaban. Salvador Alcántara, pastor de la Iglesia Evangélica Cuadrangular de El Garzal, corregimiento de Simití, quien en otro tiempo había tenido relación con Barreto, decidió buscarlo -sobreponiéndose a su temor-, para hablar con él y preguntarle sobre la realidad del rumor.

Tras varios intentos, por fin lo halló en la puerta de entrada del hospital de Simití. El diálogo fue directo y emotivo. El paramilitar le informó que había llegado para "recuperar sus tierras", y aún más, para apoderarse de todas las tierras de la región (unas 20.000 hectáreas); dio un plazo de tres meses y anunció que quien osara enfrentarse se arriesgaba a ser ultimado y arrojado al río Magdalena. ${ }^{1}$

La discusión se prolongó por varios minutos, y tuvo el segundo episodio una semana más tarde, durante un encuentro casual. Salvador desistió de persuadirlo, al darse cuenta de que Barreto no estaba dispuesto a ceder y de que la única opción que daba era el soborno. El pastor estaba muy angustiado. Aunque le dijo a Barreto que no iba a transmitir ningún recado suyo a la gente, sentía que no podía dejar las cosas así. Por eso, optó por reunir a los líderes de la comunidad; muchos de ellos eran miembros de la Iglesia Cuadrangular, presente en la localidad por veinte años; ellos estaban dispuestos a resistir, pero de momento no sabían cómo hacerlo y el miedo era grande.

Esta actitud parece extraña en una tradición religiosa caracterizada por separar lo mundano de lo espiritual, lo perteneciente al mundo de lo divino. Y es que el pentecostalismo en Colombia y en América Latina suele identificarse con una acción que privilegia el cambio personal e individual sobre el social, y que suele oponerse a la acción de transformación social, al cambio sociopolítico, al calificarlo de ser ajeno al ser del cristianismo.

Se trata de una corriente que, si decide participar en política, lo hace sin oponerse al sistema, sin criticar las problemáticas sociales y políticas, y con actitud de defensa de las autoridades constituidas, interpretando el pasaje evangélico de "dar a Dios lo

${ }^{1}$ Alcántara, Entrevista, parte 3, 19 de septiembre de 2014. 
que es de Dios y al Cesar lo que es del Cesar" (Lc20,25) en sentido de no cuestionar al sistema hegemónico. La identidad cristiana pentecostal ha estado construida, entonces, a partir de la vivencia de la fe en sentido individual y espiritualista, con poco énfasis en la dimensión sociopolítica y menos aún si se trata de cuestionar el orden vigente.

Sin embargo, lo que se cuenta en las siguientes páginas narra algo distinto. Es la historia de una comunidad compuesta por más de 350 familias que, desde su fe cristiana, decidió enfrentarse a un enemigo muy poderoso que buscaba desplazarla de sus tierras e incluso exterminarla. Es la historia de un proceso que aún no termina, pero que ha librado ya muchas batallas exitosas, que es singular y representativo a la vez, y que se ha convertido en ejemplo para otras comunidades que ven cómo la fe puede ayudarlos a empoderarse, a iniciar procesos de resistencia y desarrollo social y económico, si se convencen de que efectivamente Dios guía sus pasos.

¿Qué factores llevaron a este cambio, que ha implicado construir una nueva identidad y estilo del ser cristiano y ciudadano? ¿Cómo se desarrolló el proceso? ¿Qué consecuencias generó este cambio de orientación?

Para responder a estas preguntas utilizamos la metodología propia de la memoria histórica, que privilegia la perspectiva de los sujetos y que busca servir de instrumento de esclarecimiento de sucesos dolorosos o de victimización que la versión oficial omite y descuida, básico para conocer la verdad y emprender procesos de reparación. Además, rescata y difunde los aspectos que ayudan a una pedagogía de la ética, la esperanza, la fortaleza, el perdón y la paz, claves para la reconstrucción de una sociedad democrática, pacífica y pacifista.

Finalmente suscribimos la idea de que los derechos a la memoria y al reconocimiento de la verdad son derechos inalienables de las víctimas y de la sociedad, y de que contribuyen a su empoderamiento. ${ }^{2}$ En la recuperación de esta memoria histórica de la comunidad de El Garzal se utilizaron entrevistas grupales, individuales (historias de vida) y talleres de construcción de la memoria, según la metodología estipulada y recomendada por el Centro Nacional de Memoria Histórica. ${ }^{3}$

Queremos resaltar otras facetas del papel que juega la religión frente al fenómeno de violencia, más directamente ligadas a una ética de servicio y amor predicada por la mayoría de los grupos religiosos. Y si, efectivamente, en otras épocas, actores y causas religiosas contribuyeron a alimentar el fenómeno ${ }^{4}$, en las últimas décadas se

\footnotetext{
${ }^{2}$ Riaño y Wills, Recordar y narrar. Herramientas para reconstruir memoria histórica, 54. ${ }^{3}$ Ibid.

${ }^{4}$ Ver a Figueroa y Plata, “Acteurs religieux pendant l'époque de La Violencia en Colombie, 1945-1965”.
} 
han evidenciado prácticas y actitudes de resistencia que merecen ser rescatadas por su valor pedagógico en la búsqueda de la paz y la reconciliación.

Todo ello nos permite preguntarnos sobre los modelos de paz que se plantean desde la fe y cómo se han constituido en alternativas a la situación del conflicto armado colombiano. ${ }^{5}$ Por eso, estudiar casos de procesos de resistencia desde la fe nos ayuda a construir memoria sobre sus procesos particulares, en el marco de elaboración de una memoria histórica del conflicto armado colombiano, y a mostrarlos como ejemplos de lo que las iglesias y comunidades de fe pueden realizar, de cómo -en sus actos de resistencia- generan una nueva ética que incide en la construcción de una sociedad democrática, autónoma, madura y que cree en sí misma. Sin tales elementos es muy difícil poder "pasar la página" de más de doscientos años de guerra en nuestro país, con todas sus enormes consecuencias.

\section{El contexto y los actores}

\section{El Garzal}

El Magdalena Medio es una región ubicada en el centro-norte de Colombia, entre las cordilleras Central y Oriental. Se trata de un valle surcado por el río Magdalena, con una extensión de 120 kilómetros de ancho y 300 kilómetros de longitud. La región es cálida (con temperaturas entre los 30 y $40^{\circ} \mathrm{C}$ ) y húmeda $(70 \%$ a $80 \%)$. Fue colonizada a partir de finales del siglo XIX, debido a sus condiciones climatológicas, que la hacían poco habitable por ser propicia a enfermedades tropicales que solo la medicina moderna y los avances tecnológicos lograron controlar.

Solo existen unos treinta municipios en toda la región, de los cuales solo uno, Barrancabermeja, puede considerarse ciudad (230.000 habitantes). Junto a las cabeceras municipales, existen pequeños poblados y caseríos donde campesinos descendientes de colonos provenientes de las costa caribe y de los andes centrales y occidentales se ganan la vida en labores de pesca, minería, ganadería y agricultura. Pese a la abundancia de recursos naturales (pesqueros, madereros, mineros, fauna, flora), las condiciones de vida son difíciles para muchos de ellos. El río Magdalena suele ser la principal, y a veces, la única vía de comunicación.

A pesar de la construcción social del territorio, el Magdalena Medio no constituye una entidad administrativa: la región se encuentra circunscrita en cinco departa-

\footnotetext{
${ }^{5}$ Molina, "Resistencia comunitaria y transformación de conflictos. Un análisis desde el conflicto político-armado colombiano”, Atenea digital 6 (2004): 4. Disponible en: Redalyc, http://www.redalyc. org/articuloBasic.oa?id=53700637 (consultado el 11 de noviembre de 2014).
} 
mentos: Santander, Bolívar, Cesar, Antioquia y Boyacá. Sus condiciones geográficas han marcado esta zona como región de "frontera" donde la presencia del Estado ha sido débil y precaria. Esto ha favorecido la irrupción de problemáticas propias de tal situación: contrabando, cultura de la ilegalidad, y por supuesto, presencia de grupos armados ilegales.

La guerrilla del ELN fue la primera en llegar, y se estableció allí desde los años 60; la de las FARC también hizo presencia a partir de los años 70, y compitieron entre sí por el control del territorio. En los años 80 llegaron los paramilitares, provenientes de la costa atlántica (norte) y de la región de Puerto Boyacá (sur). Estos, como una tenaza, rodearon y sitiarona Barrancabermeja, considerada fuente de movimientos sociales, por lo cual se convirtió en principal "premio" para quienes se proclamaban adalides de la contrainsurgencia.

El Garzal es un corregimiento que pertenece al municipio de Simití, al sur del departamento de Bolívar, y comprende unas 25.000 hectáreas. Como sucede con muchas aldeas de su tipo, las comunicaciones no son buenas. Afortunadamente existe el río Magdalena. Para llegar a El Garzal desde Barrancabermeja es necesario tomar una lancha de pasajeros, por dos horas y media, y andar $90 \mathrm{~km}$ en dirección norte, hasta el corregimiento de Vijagual (municipio de Puerto Wilches), recorrido durante el cual se disfruta, por lo demás, de un paisaje maravilloso.

Luego, se atraviesa el río (por 15-20 min.) hasta la otra orilla. La entrada del corregimiento se hace por la vereda Nueva Esperanza, y a partir de allí se inicia un recorrido a través de lo que los habitantes del lugar llaman "la Muralla", la vía de comunicación que va desde la orilla del río hasta al Cerro, un camino fangoso que se puede recorrer en motocicleta en tiempo seco y a cuyos costados se encuentran las casas que componen el corregimiento.

La población de El Garzal está formada por 357 familias aproximadamente, que suman unas 1.500 personas. El corregimiento no posee área urbana definida, aunque tiene un pequeño núcleo integrado por una veintena de viviendas alrededor de la escuela y de la cancha de fútbol. Allí también hay un par de tiendas, donde se adquieren elementos básicos de consumo, traídos de municipios vecinos. Las demás viviendas están ubicadas en parcelas rurales, aunque están relativamente cerca las unas de las otras.

El nombre de El Garzal se origina porque las garzas y otros pájaros llegan en gran número a establecer sus ponederos y a dormir en las ciénagas del lugar. Esta fue una región selvática rica en maderas de todo tipo y también en jaguares, zancudos y mosquitos; y como se inundaba con frecuencia, debido a las crecientes del río Mag- 
dalena, eran pocas las personas que se aventuraban a vivir ahí antes de la década de los 60, cuando inició la colonización.

La primera actividad económica rentable fue la explotación de maderas comerciales. También se aprovechaba la abundante pesca obtenida en los canales y en el río mismo. Poco a poco se fue sembrando maíz, arroz y plátano. ${ }^{6} \mathrm{La}$ deforestación irracional, la sedimentación del río y la construcción de diques permitieron el asentamiento y la colonización, pues las condiciones del lugar se hicieron más habitables, pero también produjeron la disminución de los recursos naturales, como la pesca, que ya dejó de ser fuente de sostenimiento económico.

La organización de la comunidad ha permitido, además, diversificar la producción agrícola, con los cultivos de maíz, arroz, mango, coco, banano, fríjol, plátano, yuca y especialmente cacao, principal producto agrícola, en el cual se ha puesto muchas esperanzas, gracias a proyectos financiados por entidades extranjeras, que han integrado a unas ochenta familias. En 2013 existían unas 250 hectáreas sembradas, con un promedio de producción mensual de doce toneladas. ${ }^{7}$

Aunque aproximadamente la mitad de los habitantes de El Garzal son "católicos poco practicantes", la otra mitad pertenece a iglesias cristianas de origen protestante. ${ }^{8}$ La más activa es la Iglesia Internacional del Evangelio Cuadrangular, más conocida como Iglesia Evangélica Cuadrangular, denominación cristiana de línea pentecostal fundada en 1923 en Los Ángeles, Estados Unidos, que llegó a Colombia en los años 40, para establecerse en zonas rurales de los departamentos de Santander y Norte de Santander, y luego en el Magdalena Medio. ${ }^{9}$

Por tanto, puede considerársele como una iglesia copartícipe de los procesos de colonización y evangelización de la comarca. La Iglesia Cristiana Evangélica Cua-

\footnotetext{
${ }^{6}$ Molano, "Caso El Garzal", Diario El Espectador, Bogotá, 17 de diciembre de 2011, http://www. elespectador.com/noticias/nacional/campesinos-narcos-y-humedales-articulo-317232 (consultado el 10 de octubre de 2014).

${ }^{7}$ Alcántara, Entrevista, parte 1, 7 de septiembre de 2013.

${ }^{8}$ Junto al tardío inicio de la evangelización católica se da la llegada a la región de misiones protestantes de línea evangélica, provenientes de Estados Unidos, especialmente a partir de los años 40 y 50 . También arriban adventistas, testigos de Jehová y los pentecostales unitarios. Una de los grupos religiosos de más temprana presencia en la zona es la Iglesia Evangélica Cuadrangular, de línea pentecostal trinitaria. A partir de los años 70, varias de estas iglesias rompen sus vínculos con las iglesias madre de Estados Unidos y se vuelven independientes y autónomas, lo que significa asumir formas y costumbres adaptadas a la idiosincrasia local. Estas iglesias suelen estar donde el catolicismo es débil, y logran convertirse en comunidades de fe que dan sentido a la vida de muchas personas marginadas y dispersas en las riberas del gran río.
}

${ }^{9}$ Thompson, "Establishment and Growth of Protestantism in Colombia", 90-91. 
drangular se divide en Colombia en cuatro distritos. El Garzal está adscrito al Distrito Central. Salvador Alcántara es uno de los quinientos pastores con los que esta Iglesia cuenta en todo el país. Es de las pocas iglesias en Colombia cuyos miembros siguen denominándose a sí mismos "evangélicos". ${ }^{10}$

\section{Salvador}

Salvador Alcántara nació en Barbosa (Bolívar). Hijo de madre conservadora y padre liberal radical, desde niño recibió una formación política particular, a pesar de que su única educación formal fue la escuela primaria. A los catorce años salió de su casa, y tras un periplo por Bucaramanga y otras zonas, en 1981, se convirtió al cristianismo pentecostal, en San Pablo, Bolívar, y dejó su vida "disoluta" de antaño. ${ }^{11}$

Su proceso como cristiano evangélico tuvo dos etapas. Primero llegó a la Iglesia Pentecostal Unida de Colombia y luego se pasó a la Iglesia Evangélica Cuadrangular, que consideró más sólida doctrinalmente. Las condiciones intelectuales y personales de Salvador hicieron que pronto destacara dentro de la Iglesia, de manera que en poco tiempo inició un proceso de formación para convertirse en pastor, función en la que se destacado por su capacidad organizativa y los buenos resultados en materia de crecimiento de fieles.

La historia de vida de Salvador presenta a una persona con capacidad de liderazgo natural, con formación política particular, de espíritu abierto, crítico y razonador. Es alguien que, una vez se convence de una idea, toma decisiones y actúa en consecuencia. Tras convertirse, estudió a profundidad la Biblia con ese mismo espíritu y tratando de relacionar su fe con la sociedad que lo rodeaba. Por ello, reaccionó contra las posiciones integristas de numerosos los miembros de su Iglesia y a la oposición Iglesia-mundo:

Eran evangélicos radicales, o sea, que todo para ellos es pecado, inclusive era de los que no saludaban a uno que no era evangélico porque se contaminaban. ${ }^{12}$

En 1995, Salvador llegó a pastorear a la Iglesia Evangélica Cuadrangular de El Garzal, donde se destacó rápidamente por su particular visión del mundo y de la

\footnotetext{
${ }^{10}$ Durante mucho tiempo, "evangélico" fue un término despectivo, con el cual se hacían señalamientos y discriminaciones por parte de los católicos. Por eso, la mayoría de las iglesias cristianas de origen protestante no históricas convinieron en llamarse a sí mismas simplemente "cristianas", y así se les conoce hoy día en Colombia.

${ }^{11}$ Alcántara, Entrevista, parte 1, 7 de septiembre de 2013. Salvador Alcántara se consideraba a sí mismo como "parrandero y mujeriego".

${ }^{12}$ Ibid., 21.
} 
sociedad, así como por sus esfuerzos en cualificar la formación religiosa de los fieles y en organizar la comunidad en torno de proyectos de desarrollo social y económico.

La historia personal del pastor Salvador Alcántara le invitaba a buscar conectar el Evangelio con la realidad social. Él había tenido una formación en la cual se le inculcaron principios de crítica social, que después compaginó con sus creencias, de manera que para él es muy natural preguntarse sobre las consecuencias sociales de la fe.

Salvador suele recalcar en sus homilías dominicales este vínculo y este compromiso, que ve muy claro en la Biblia. También dio una organización más comunitaria y democrática a su iglesia, de manera que existan equipos coordinadores para distintos asuntos. Esto no es común entre las iglesias cristianas de línea pentecostal en Colombia, acostumbradas al liderazgo carismático y centralizado. ${ }^{13}$

Según el teólogo y sociólogo Fabio Lozano, quien realizó una encuesta entre las iglesias cristianas de origen protestante afiliadas a la Confederación de Iglesias Evangélicas de Colombia, Cedecol, al dar mucho interés al milenarismo, se considera que se deben preparar para el fin; por tanto, no consideran útil desgastarse en intentar cambiar los contextos del presente, que de todos modos van a finalizar con la Parusía. ${ }^{14}$

Otro factor es la interpretación que se hace de las cartas paulinas, en lo que respecta a su petición de obedecer a las respectivas autoridades. De esta tendencia se apartan un poco las iglesias protestantes "históricas"15, en especial la menonita. A pesar del pequeño número de sus miembros en Colombia, esta se ha destacado en desempeñar una vasta labor en torno de la búsqueda de la paz y de resistencia noviolenta a la guerra, algo por lo que es reconocida en el ámbito internacional. ${ }^{16}$

Sin embargo, a mediados de los años 90, en El Garzal, Salvador debía sentirse muy solo en el pensamiento y accionar que procuraba dar a la iglesia que pastoreaba. Ir a contracorriente no dejaba de generarle muchas dudas. ${ }^{17}$

\footnotetext{
${ }^{13}$ Idem, parte 2, 9 de septiembre de 2013, 17-18.

${ }^{14}$ Lozano, "Evangélicos y pobreza. Reflexiones a partir del estudio de la acción social de las iglesias evangélicas en Colombia”, 259.

${ }^{15}$ Bajo el término protestantismo histórico se incluyen las iglesias nacidas directamente de la Reforma Protestante, en los siglos XVI a XVIII. Entre ellas se encuentran los luteranos, los calvinistas, los presbiterianos, los metodistas, los bautistas y las iglesias de la corriente anabaptista, como los cuáqueros y los menonitas.

${ }^{16}$ Stucky, Bases bíblico-teológicas del quehacer de las iglesias en la construcción de la Paz. Tres iglesias santuarios de paz de la costa Caribe de Colombia presentan sus experiencias y aprendizajes, 43; Gafaro y Stucy, Construyendo la paz. Aprendizajes desde la base. El conflicto colombiano y las iglesias santuarios de paz. Tres iglesias santuarios de paz de la costa caribe de Colombia presentan sus experiencias y aprendizajes.

${ }^{17}$ Alcántara, Entrevista, parte 2, 9 de septiembre de 2013, 6.
} 


\section{Los paramilitares}

Los paramilitares, integrados desde 1995 en una coordinadora denominada Autodefensas Unidas de Colombia, llegaron al sur del departamento de Bolívar a comienzos de 1998. Los dirigía Rodrigo Pérez Alzate, alias Julián Bolívar. Esta incursión, al parecer, se hizo con la complicidad de la policía, que se retiró para permitir el ingreso de las fuerzas irregulares, y después les entregó la vigilancia de la zona. ${ }^{18}$ Además, contaron con el apoyo de antiguos guerrilleros que se cambiaron de bando y vivían en la zona, conocían bien el terreno y las estructuras de las guerrillas. ${ }^{19}$

Entre los paramilitares que llegaban se encontraba un viejo conocido de la gente de El Garzal: Manuel Enrique Barreto, quien adoptaba el alias de Don Pedro. Él había hecho presencia en la región en la década de los 80, había adquirido miles de hectáreas por medios ilegales y había fundado una hacienda que utilizaba para el cultivo y procesamiento de cocaína, que luego exportaba al extranjero utilizando una pista aérea que construyó en sus predios y que aún hoy día existe. Luego, había tenido que alejarse de la zona, en tiempos de la lucha del Estado colombiano contra el Cartel de Medellín, para el cual, al parecer, trabajaba Barreto.

Tras su ausencia, los campesinos ocuparon las tierras que les pertenecían y que el presunto narcotraficante había usurpado. De acuerdo con la versión libre dada al portal Verdad Abierta, en 2009, por el exjefe paramilitar Pérez Alzate y otras declaraciones hechas en su juicio, el paramilitarismo ingresó en el sur de Bolívar bajo aliento y petición de Manuel Barreto. ${ }^{20}$

Por ese tiempo, el río Magdalena se volvió tristemente célebre por servir de "cementerio" de cadáveres de personas asesinadas por los violentos, que bajaban, uno tras otro, día tras día. "Los cadáveres flotaban en el río. Los veíamos pasar cada día, a veces varias veces al día”, recuerda Salvador. "A veces los encontrábamos abandonados en la orilla. Durante años enteros, yo no podía ver estas aguas sin ver el reflejo de las caras de esas víctimas inocentes." ${ }^{21}$

\footnotetext{
${ }^{18}$ Verdad Abierta, "Nos convertimos en una máquina de matar: Julián Bolívar", Verdad Abierta, Conflicto armado en Colombia (29 de octubre de 2009), www.verdadabierta.com/.../1903-qnos-convertimos-enuna-maquina-de- matarq-julian-bolivar (consultado el 26 de agosto de 2014).

${ }^{19}$ Castilla, Entrevista, 7 de febrero de 2014, 37.

${ }^{20}$ Verdad Abierta, "Nos convertimos en una máquina de matar: Julián Bolívar", Verdad Abierta, Conflicto armado en Colombia (29 de octubre de 2009), www.verdadabierta.com/.../1903-qnos-convertimos-enuna-maquina-de- matarq-julian-bolivar (consultado el 26 de agosto de 2014).

${ }^{21}$ Citado por Summermatter, "Un campesino sin tierra es como un pez fuera del agua", Swissinfo.ch (17 de septiembre de 2011), http://www.swissinfo.ch/spa/-un-campesino-sin-tierra-es-como-un-pez-fueradel-agua-/31058248 (consultado el 26 de agosto de 2014).
} 
Todo el accionar del paramilitarismo en la zona se financió con coca, básicamente extorsionando a los dueños de laboratorios y a los compradores. Así, reconoce Pérez Alzate: "Nos convertimos en una máquina de matar, en una maquina generadora de empleo que entregaba licencias para matar."22

\section{La amenaza y la revelación}

No acababan de entrar los paramilitares a la región cuando empezó a cundir el rumor de que Barreto venía "por sus tierras". ${ }^{23}$ Por eso, la comunidad decidió actuar y pidió al Estado verificar si dichas tierras pertenecían o no al presunto paramilitar; se le respondió que se trataba de terrenos baldíos, por lo cual se solicitó iniciar el proceso de titulación de los predios que ya ocupaban los campesinos, inclusive desde los años 70 . Los primeros resultados positivos de tal gestión solo se dieron tras siete años de iniciada esta.

Mientras tanto, solo había rumores, pues por razones de índole estratégico Barreto debió esperar cuatro años para actuar contra los habitantes de El Garzal. Finalmente, en 2003, Barreto les mandó decir que se marcharan, pues ahora sí iba a entrar. Para mostrar que hablaba en serio, contrató trabajadores que amedrantaran a los pobladores mediante rumores y saboteo de cultivos. ${ }^{24}$

La zozobra cundía por doquier. La gente evitaba salir de casa y todos esperaban que cualquier día llegara un grupo armado a sacarlos o a asesinarlos. Cuando ladraban los perros en la noche, se esperaba lo peor. Eran días de gran angustia.

Dos funcionarios de Swissaid, una organización no gubernamental suiza que desde tiempo atrás venía colaborando con proyectos sociales en El Garzal, buscaron entrar en diálogo con Barreto, pero este los desconoció como interlocutores. ${ }^{25}$ Fue entonces cuando Salvador intervino. Años atrás había conocido a Barreto e inclusive había tratado de convertirlo al evangelismo, sin éxito. Creía que, dados estos antecedentes, podía convencerlo, alegando principios éticos y cristianos; pero este esfuerzo fue vano.

Entonces, Salvador optó por iniciar la resistencia. Comenzó adoptando una actitud desafiante. Evitaba bajar la cabeza ante el agresor, y no solo durante los diálogos

\footnotetext{
${ }^{22}$ Verdad Abierta, "Nos convertimos en una máquina de matar: Julián Bolívar", Verdad Abierta, Conflicto armado en Colombia (29 de octubre de 2009), www.verdadabierta.com/.../1903-qnos-convertimos-enuna-maquina-de- matarq-julian-bolivar (consultado el 26 de agosto de 2014).

${ }^{23}$ Alcántara, Entrevista, parte 3, 19 de septiembre de 2013, 11.

${ }^{24}$ Mendoza y D. Alcántara, Entrevista, $1^{\circ}$ de marzo de 2014, 6-7.

${ }^{25}$ Taller de Construcción de Línea del Tiempo con la Comunidad de El Garzal, 28 de febrero de 2014.
} 
con Barreto, sino en otros episodios que ocurrían casi simultáneamente. Esta es una actitud poco común en alguien que tenía todo que perder, que podría terminar asesinado o desplazado. El hecho de haber conocido a Barreto la explica en parte; pero también tuvo que ver su fe, la manera como interpretaba las cosas.

Porque al tiempo que se daban tales diálogos y se adquiría claridad sobre la gravedad la situación que sobrevenía a la comunidad, Salvador fue más allá de mostrar altivez y convocó a la junta de Acción Comunal para hablarles con franqueza de lo que sucedía. Tras narrar su conversación con Barreto y la amenaza proferida por él, procedió a invitar a la resistencia, basada en la confianza en Dios:

La situación es dificil; asi que ustedes deben de ponerse al frente de esto, y buscar mecanismos cómo se enfrenta esta situación [...] yo creo que aqui nadie se debe llenar de miedo; nosotros tenemos un Dios real, un Dios que está con nosotros, tenemos que creer en eso y que Dios puede ayudar aquí; el único que puede ayudarnos se llama papá Dios. $^{26}$

La asamblea nombró a Salvador como su representante y coordinador del proceso de resistencia, lo cual lo llevó a asumir un triple liderazgo: político-social, comunitario y religioso.

¿Qué hacer ahora? Pedir ayuda. ¿A quién? La comunidad solo tenía tres tipos de vínculos que podrían ayudarla: las organizaciones comunitarias locales vía juntas de Acción Comunal, la red de la Iglesia Evangélica y la Asociación de Productores Alternativos de Simití, Asproas, asociación de campesinos que procuraba el desarrollo económico de la región.

Los vínculos que la Iglesia tenía entonces no eran claros, en lo que se refería al apoyo social y político a un proceso de resistencia contra un actor armado, y los de la Acción Comunal eran por lo general de tipo político local y regional, y no servirían para enfrentar a una estructura paramilitar que permeaba al Estado y a los estamentos políticos regionales y locales. Por tanto, se recurrió a tocar las puertas de las redes de apoyo de Asproas.

La Asociación de Productores Alternativos de Simití, Asproas, está compuesta por unos quinientos campesinos. Esta sería la entidad que serviría como aglutinadora de esfuerzos y recursos para el proceso de resistencia a la invasión paramilitar. Había

${ }^{26}$ Alcántara, Entrevista, parte 3, 19 de septiembre de 2013, 16. 
nacido en 1997 bajo la iniciativa del sacerdote católico francés Clément Berel ${ }^{27}$, con el fin de generar proyectos agrícolas sostenibles, rentables y respetuosos con el medio ambiente.

Dicho clérigo se vio obligado a salir de la zona luego de la incursión paramilitar, ya que -como acostumbraba a caminar por los campos visitando a las familias- fue acusado de apoyar a la guerrilla y su nombre apareció en una lista negra de los paramilitares. Berel alcanzó, sin embargo, a proporcionar a Asproas algunos contactos internacionales que luego respaldarían la resistencia ejercida por la comunidad de El Garzal. Uno de estos contactos fue la organización suiza denominada Swissaid.

Salvador entró en contacto con el Programa de Desarrollo y Paz del Magdalena $\mathrm{Medio}^{28}$, el cual asumió con rapidez el caso y programó reuniones en las que ofreció total apoyo a la comunidad. Sin embargo, infiltrados de los paramilitares comunicaron a sus jefes lo que sucedía, de manera que Salvador recibió amenazas de muerte para $\mathrm{y}$ presiones, por medio de funcionarios gubernamentales locales corrompidos por el dinero y las armas de los paramilitares. ${ }^{29}$

El miedo seguía a la orden del día. No se sabía cuánto tiempo se podría resistir a todo ello. Nidia Alian, la esposa de Salvador, le rogaba que se marcharan de El Garzal cuanto antes. ${ }^{30}$

Solo quedaba acudir a Dios, en quien ellos tanto confiaban y cuyas promesas hechas en la Biblia -que leían cada día y analizaban cada semana en el culto dominicalhablaban de vencer a los enemigos, de humillar al soberbio, de exaltar al humilde. Por ello, de manera individual y colectiva, los miembros de la Iglesia Evangélica del Garzal realizaron vigilias de ayuno y oración, hasta altas horas de la madrugada, pidiendo la intervención divina.

Una noche del mes de febrero de 2004, hacia las dos de la madrugada, mientras vigilaba con su esposo, Nidia tuvo una particular experiencia:

\footnotetext{
${ }^{27}$ Clément Bérel, sacerdote perteneciente a la arquidiócesis de Rennes, Francia, llegó como misionero a América Latina en 1972. Vivió en Honduras y luego en Colombia. Falleció el 19 de noviembre de 2014 en Cartagena de Indias. Ver Dans no coeurs, "Clemént Berel”, Dansnosceurs.fr, http://www.dansnoscoeurs. fr/clement-berel/1213804 (consultado en 2 de diciembre de 2014).

${ }^{28}$ El Programa de Desarrollo y Paz del Magdalena Medio fue creado en 1995 por la Compañía de Jesús, la Diócesis de Barrancabermeja y la Empresa Colombiana de Petróleos, Ecopetrol. Su área de influencia cubre 29 municipios del medio y bajo Magdalena, y se inserta en la vida del territorio para generar dinámicas favorables al desarrollo y la paz.

${ }^{29}$ Alcántara, Entrevista, parte 3, 19 de septiembre de 2013, 20.

${ }^{30}$ Alian y A. Alcántara, Entrevista, $1^{\circ}$ de marzo de 2014, 3.
} 
... Dios me tomó a mí, Dios me tomó; cogió las cuerdas vocales y yo hablé... Le decía a él que no tuviera miedo, que Dios estaba con él, que él lo habia mandado a este lugar para eso, para un proceso, para este proceso, de estas tierras, que únicamente no lo habia mandado para que fuera pastor sino para que él se pusiera al frente de todo esto, y... y que no tuviera miedo, que no tuviera temor, porque Dios estaba con él, y que le mandaria legiones de ángeles para que le guardaran, para que nos guardaran, y... y que él iba a mandar much gente, de muchos paises, de otras partes, que nosotros no nos imaginábamos. ${ }^{31}$

Salvador, quien había pensado que su decisión de resistir a Barreto era un capricho suyo, comenzó a llorar, y su esposa siguió hablando:

Sigan orando, sigan ayunando, porque yo estoy con ustedes; yo voy a traer mucha gente, tú vas a ir a lugares que ni tú te imaginas, porque yo voy a demostrar de que yo soy Dios y voy a demostrar mi gloria, y muchos tendrán que reconocer que yo estoy con usted y no tengas miedo porque yo me voy a glorificar. ${ }^{32}$

Al finalizar la experiencios aqui, así como hicimos con los animales lo vamos a hacer con ustedes. ${ }^{33}$

Salvador pidió a la comunidad no dejarse vencer por el miedo, por lo cual relató -en varias oportunidades- la experiencia sobrenatural vivida. La mayoría de las personas creyeron en las revelaciones recibidas por Nidia y Salvador, pero algunos se mostraron escépticos y optaron por marcharse.

Así es como las dudas y el miedo cedieron ante la promesa y el ánimo divino que pedía resistir, y que -de acuerdo con los testimonios- fue mostrando en poco tiempo resultados inesperados. Uno de ellos fue precisamente un evento calificado por todos como milagro. Según los testimonios, en varias ocasiones, en 2004, el grupo paramilitar había recibido la orden de entrar al Garzal y masacrar a la población. Sin embargo, además de escuchar disparos del ejército, un temor sobrenatural hizo que los bandidos, una vez desembarcaron y se dispusieron a marchar sobre El Garzal, dieran marcha atrás y se regresaran. ${ }^{34}$

${ }^{31}$ Ibid.

32 Alcántara, Entrevista, parte 3, 19 de septiembre de 2013, 21.

${ }^{33}$ Ibid., parte 4, 20 de septiembre de 2013, 5.

${ }^{34}$ Testimonio de Samuel Mendoza, citado por Paz, (dir. y prod.), "Salvador" [video documental]. 
Finalmente, Salvador cuenta que él mismo se encontró con un paramilitar desmovilizado, quien le expresó su sorpresa por hallarlo vivo y le dijo que si bien había tenía órdenes de matarlo, no había sido capaz de hacerlo. ${ }^{35}$

Estos acontecimientos son claves para comprender hasta qué punto la comunidad se convenció de que Dios efectivamente estaba con ella y guiaba el proceso de resistencia.

\section{La resistencia}

\section{La lucha por la titulación de las tierras}

Por medio de Asproas y del Programa de Desarrollo y Paz se lograron contactos nacionales e internaciones, con los cuales se logró que las autoridades gubernamentales conocieran y tuvieran en cuenta la situación. Así, llegaron a la población Acnur-ONU, Swissaid, Suippcol ${ }^{36}$, Justapaz ${ }^{37}$, los Equipos Cristianos de Acción por la Paz, ECAP, ${ }^{38}$ y la Pastoral Social de la diócesis de Barrancabermeja ${ }^{39}$, entre otros.

El acompañamiento de organizaciones externas permitió a la comunidad contratar los servicios de abogados para que ayudaran con el proceso de titulación de tierras iniciado en 1998, que marchaba con gran dificultad. Todo ello hizo que el gobierno nacional prestara atención al caso de El Garzal, lo que sirvió para que las reclamaciones de los campesinos fueran atendidas por organismos estatales y que el caso fuera incluido entre iniciativas gubernamentales creadas para proteger a la población desplazada.

\footnotetext{
${ }^{35}$ Miller-Eshleman, "Salvador Alcántara”, Bearing Witness. Stories Project (11 de octubre de 2014), http:// www.martyrstories.org/salvador-alcantara-2/?lang=es (consultado el 15 de noviembre de 2014).

${ }^{36}$ El Programa Suizo para la Promoción de la Paz en Colombia, Suippcol, fue creado en 2001. Es un programa de la sociedad civil suiza con un fuerte apoyo del gobierno suizo. Respalda prioritariamente organizaciones o procesos locales, sobretodo, en el campo, que se encuentran en las zonas de conflicto.

${ }^{37}$ La Asociación Cristiana Menonita para Justicia, Paz y Acción Noviolenta, Justapaz, se fundó en 1990, y ha sido reconocida por la promoción de estrategias de resistencia noviolenta, desde las iglesias, a los grupos armados.

${ }^{38}$ Los Equipos Cristianos de Acción por la Paz, ECAP, surgidos de la iglesias Menonita, los Hermanos Menonitas y Quáquera, apoya a toda comunidad cristiana que busca alternativas noviolentas a la guerra mediante una red amplia y ecuménica que incluye acciones de paz basadas en la Biblia, que den testimonio al público, que sean directas y noviolentas, y que protejan los derechos humanos.

${ }^{39}$ La Pastoral Social de la diócesis de Barrancabermeja surge en 1972 como apuesta por traducir el mensaje evangélico en solidaridad y acción social concreta, con proyectos de desarrollo económico y social, la formación de líderes, la defensa de los derechos humanos y la promoción de la paz con justicia social.
} 
El principal frente de lucha fue la búsqueda de titulación de las tierras que los campesinos de El Garzal habitaban desde la década del 60. Hacia 2006, el año de la desmovilización de las Autodefensas Unidas de Colombia, AUC, corrió el rumor de que Barreto había fallecido: algunos decían que por un accidente de tránsito; otros, que por un asesinato; unos más, que por una enfermedad. ${ }^{40}$ Lo cierto es que no se volvió a tener noticias suyas.

La comunidad, sin embargo, no confía en la veracidad de estos rumores. Algunos creen que Barreto simplemente buscó el anonimato debido a que sus acciones criminales iban más allá del paramilitarismo y no sería cobijado por la Ley de Justicia y Paz que reglamentó la desmovilización de estos grupos. En los hechos, Barreto no se desmovilizó, y la investigación acerca de su supuesta muerte no se ha realizado.

Sea como fuere, a partir de entonces, la comunidad entró en una tenaz lucha jurídica con los herederos de Barreto, así como parientes, amigos y aliados suyos, que a título personal o por medio de empresas palmicultoras ${ }^{41}$ entablaron demandas contra los campesinos de El Garzal, con el argumento de que habían invadido "sus" tierras, en las que los calificaban de guerrilleros.

El proceso jurídico había iniciado dos años antes, el 24 de febrero de 2004, cuando se interpusieron ocho demandas posesorias contra la comunidad del corregimiento, pese a la existencia de más de sesenta títulos de propiedad que estaban listos para ser entregados a los campesinos por el Estado ${ }^{42}$, fruto del proceso iniciado desde finales de los años 90 .

Este cambio de estrategia seguramente tuvo que ver, por una parte, con la proximidad del proceso de desmovilización las AUC (a la cual pertenecía Barreto), lo que pondría dificultades a la hora de hacer una entrada a sangre y fuego en el corregimiento. Por otra parte, la llegada de entidades nacionales e internacionales a acompañar el caso, hizo que actuar abiertamente contra los campesinos fuera contraproducente con el proceso de desmovilización y con la imagen misma del gobierno que lo apoyaba.

Por ello, la estrategia a seguir sería la lucha jurídica, acompañada de amenazas periódicas a la comunidad. Esta vía se consideraba más "limpia” y también eficaz, dada la debilidad del aparato judicial colombiano, especialmente en estas regiones olvidadas por el Estado, ante el poder corruptor del dinero y la intimidación.

\footnotetext{
${ }^{40}$ Molano, "Campesinos, narcos y humedales", Diario El Espectador, Bogotá, 17 de diciembre de 2011, http://www.elespectador.com/noticias/nacional/campesinos-narcos-y-humedales-articulo-317232 (consultado el 10 de octubre de 2014).

${ }^{41}$ Ibid.

${ }^{42}$ Ibid.
} 
Al parecer, Barreto había prohibido a funcionarios locales del Estado entregar los 64 títulos que estaban listos a los campesinos, había solicitado la revocatoria de los mismos y acusado a los campesinos de invasores. Luego, los herederos de Barreto aparecieron solicitando más de 13.000 hectáreas, 4.000 más de las que comprende todo el corregimiento del Garzal. ${ }^{43} \mathrm{Si}$ la demanda prosperaba, todos los campesinos de El Garzal y de sus alrededores (más de 300 familias) tendrían que marcharse de allí.

Además de la acusación de invasión, Barreto había insistido en otro argumento: que los líderes de El Garzal eran guerrilleros. Esto causaba mucho daño en un momento en el cual el país se oponía mayoritariamente a la guerrilla, y en que el gobierno de Uribe, además de haber logrado que el gobierno de los Estados Unidos reconociera el estatus terrorista de las guerrillas colombianas, había infundido en la población la consigna de que todo aquel que procurara cambios sociales, fuera integrante de un movimiento social o de un sindicato, era colaborador o miembro de la guerrilla, del "terrorismo".

Así las cosas, la acusación de Barreto, para una comunidad como la de El Garzal, podía tener hondas consecuencias, pues además deslegitimaba toda su lucha de resistencia. ${ }^{44}$

Con el apoyo de los abogados contratados por las entidades acompañantes, la comunidad insistió en su argumento fundamental: en El Garzal, la ocupación de los campesinos llevaba más de cuarenta años, de manera continua, y eso, según la ley, era motivo suficiente para garantizar la titulación de antiguos baldíos a sus ocupantes. Además, la comunidad insistía en la ilegalidad de los títulos conseguidos por Barreto en los años 80.

Los demandantes también jugaron sus cartas, incluidas tretas jurídicas y sobornos a autoridades locales, y en diciembre de 2011 un juez de Simití revocó los títulos ya obtenidos por algunos campesinos y concedió a la familia Barreto la propiedad de las tierras en litigio ${ }^{45}$, al tiempo que Salvador Alcántara era amenazado de muerte. ${ }^{46}$

\footnotetext{
${ }^{43}$ Red de Iniciativas y Comunidades de Paz, "La comunidad de El Garzal (sur de Bolívar) denuncia posible apropiación ilegal de tierras del Estado y una amenaza de desalojo para el 13 de diciembre”, Notiagen (2011), http://www.pazdesdelabase.org/index.php?option=com_content\&view=article\&id=887:lacomunidad-de-el-garzal-sur-de-bolivar-denuncia-posible-apropiacion-ilegal-de-tierras-del-estado-yuna-amenaza-de-desalojo-para-el-13-de-diciembre\&catid=54:asproas\&Itemid=99 (consultado el 11 de junio de 2014).

${ }^{44}$ Entrevista a Samuel Mendoza, y a Dubys Alcántara, 1 de marzo de 2014, 8-9.

${ }^{45}$ Shantz, "Inspecciones y oraciones", Oración.Resistencia. Comunidad. Un blog de Equipos Cristianos de Acción por la Paz (29 de junio de 2012), http://ecapcolombia.wordpress.com/2012/06/29/inspeccionesy-oraciones/ (consultado el 7 de septiembre de 2013).
} 
No obstante, si los reclamantes de la tierra de la comunidad fueron efectivos en cooptar autoridades, a nivel local, los habitantes de El Garzal han sabido defenderse en el ámbito jurídico ante los organismos centrales del Estado. Lograron que el Incoder detuviera la revocatoria de los títulos realizada por el juez de Simití, al tiempo que dicha entidad daba la noticia de que "pronto" se iniciaría la entrega de 214 títulos de tierras, tras iniciarse un proceso en el que el Estado colombiano declara las tierras como baldíos, y por ende, del Estado, y posteriormente las titula a las familias campesinas. Los resultados comenzaron a verificarse el 4 de abril de 2013, cuando el Estado (por medio del Incoder) entregó públicamente 64 títulos de propiedad a otras tantas familias de El Garzal.

Cada victoria de la comunidad fue respondida con amenazas o acciones judiciales. Poco después de la entrega de los títulos, en mayo de 2013, Salvador tuvo que salir otra vez de El Garzal, ante nuevas amenazas, y permaneció exiliado por siete meses.

Las contrariedades continuaron: los títulos entregados en 2013 llegaron sin planos, lo cual impedía registrar legalmente las propiedades. Para completar, los campesinos supieron que las tierras de El Garzal habían sido solicitadas por foráneos en el marco de la Ley de Restitución de Tierras.

Sin embargo, parece que por fin la luz se ve al final del túnel: en marzo de 2015 se recibió la noticia de que la demanda contra la comunidad de El Garzal carecía de sustento y que el proceso llegaba a su fin. En el momento de redactar este artículo, la comunidad esperaba la entrega oficial de los títulos de propiedad a todas las familias del corregimiento.

\section{Nuevos liderazgos}

Es claro que el proceso ha contado con el liderazgo indiscutido del pastor Salvador Alcántara, tanto por el conocimiento que él tiene de sus enemigos como por sus cualidades naturales, su formación y su condición de líder religioso. Este liderazgo se consolidó con base en su temple, su fortaleza y su convicción de que Dios guiaba el proceso. Por eso no dudó en enfrentarse a sus propios escrúpulos y temores, e inclusive a su propia familia, la cual -reconoce- le pidió al comienzo, de manera insistente, que abandonara la resistencia, por miedo a que lo asesinaran. ${ }^{47}$

\footnotetext{
${ }^{46}$ Alcántara, Entrevista, parte 2, 9 de septiembre de 2013, 23.

${ }^{47}$ Entrevista a Nidia Alian y Almaida Alcántara, 1 de marzo de 2014, 12.
} 
Y una vez que el proceso de resistencia inició su marcha y aumentaron las amenazas, se determinó que debían involucrarse más personas, para que en caso de que Salvador faltara, el movimiento no se truncara. Por eso se buscó formar nuevos líderes y liderazgos, y en 2013 se contaba con unas siete personas de confianza, algunos jóvenes y otros de mayor edad a quienes se les habían delegado responsabilidades.

Dicha delegación se caracteriza por ser rotatoria, es decir, todos van haciendo lo mismo por periodos, lo que conlleva a que aprendan cómo desenvolverse en una responsabilidad. La formación de líderes ha llevado inclusive a contar con un representante en el Concejo municipal. ${ }^{48}$

La formación de los líderes se ha hecho desde la práctica (asumiendo responsabilidades concretas) pero también desde lo teórico, a partir de cursos de capacitación recibidos por el Programa de Desarrollo y Paz o Asproas, en los que se ha insistido en la autovaloración, el trabajo en grupo, la cohesión, la constancia y en saber reclamar los propios derechos de manera pacífica pero con firmeza.

Otra característica del liderazgo en este proceso ha sido la toma colectiva de decisiones. Samuel Vargas comenta que la gente decía que "quizás la parte en Colombia donde más se hacían reuniones era aquí en El Garzal”. En los primeros años, de hecho, se hacían varias reuniones por semana. Estas reuniones han sido convocadas por Asproas, la Junta de Acción Comunal y la Iglesia Evangélica Cuadrangular. También, al finalizar el culto dominical, es frecuente la llamada a los asistentes a permanecer un tiempo más, para discutir algún asunto urgente o puntual.

Así, el servicio religioso adquiere además un significado de convención comunitaria, en donde se discute -fuera de lo religioso propiamente dicho- sobre la vida cotidiana de la comunidad. Esta manera de ejercer participativamente el liderazgo ha permitido que, por ejemplo, cuando Salvador ha debido salir por largas temporadas de la región, por las amenazas en su contra, la comunidad mantenga su organización. ${ }^{49}$

Un importante rol de liderazgo ha sido ejercido por las mujeres. Si los hombres asumen la representación pública, convocan, organizan y dirigen la comunidad, las mujeres han sido animadoras religiosas, consejeras, sostén de las familias y organizadoras de la economía solidaria. En lo primero, han sido determinantes en su función como profetizas, en especial, Nidia Adián y Almaida Rojas, esposa y madre

\footnotetext{
${ }^{48}$ Alcántara, Entrevista, parte 2, 9 de septiembre de 2013, 18.

${ }^{49}$ Entrevista a Alix Crespo, publicada en Beltrán y Bartel, Rebeca (dirs.), "El Garzal: fe y resistencia" [documental en DVD], minuto 10.
} 
de Salvador, respectivamente, quienes han emulado el rol que menciona la Biblia que tenían muchas mujeres en la sociedad judía y en la comunidad cristiana primitiva ${ }^{50}$ : anunciar y animar, de parte de Dios, a la comunidad.

Sin el ejercicio de este rol -nos atrevemos a decir-, el proceso habría tenido otra suerte, pues buena parte de la capacidad de resistencia asumida por la comunidad se ha debido a que sus miembros han creído en las revelaciones transmitidas por estas mujeres. También, en las ausencias de Salvador, Nidia se responsabiliza del templo, de tener todo listo y de participar en la dirección de la Iglesia, con los demás líderes. Además, asume la familia, de manera que Salvador pueda tener libertad para ir y venir.

Un rasgo más del liderazgo femenino tiene que ver con las funciones económicas. Un grupo de unas veinte mujeres de El Garzal, con el apoyo de Asproas y bajo el liderazgo de Nidia, constituyeron la asociación femenina "El Porvenir", cuyo objetivo era ayudar a la adquisición de productos existentes en el mercado. Sin embargo, debido a las amenazas recibidas y a los exilios a que debió someterse la familia del pastor, la asociación debió cerrarse. También constituyeron una panadería comunitaria y hasta gestionaron proyectos de siembra de fríjol y hortalizas. El apoyo de base que han prestado las mujeres de El Garzal al proceso es reconocido por todos como fundamental..$^{51}$

\section{Desarrollo económico}

El proceso de resistencia ha conllevado y ha estado apoyado -las dos cosas- en proyectos de desarrollo económico sostenible. De acuerdo con Salvador, por una parte, se origina en su propia sensibilidad e inquietud personal; por otra, en una interpretación del Evangelio que cuestiona el acomodamiento e invita al servicio y al bienestar del otro; interpretación que ha sido además motivada por la crítica situación experimentada por la comunidad. ${ }^{52}$ Esto, porque todo cristiano debe sentir "compasión", es decir, dolor por el sufrimiento del otro, que lo lleve a solidarizarse con este.

El organismo articulador de los procesos de desarrollo socioeconómico ha sido Asproas, por medio del cual la comunidad gestiona el apoyo a sus programas ante organismos nacionales e internacionales, como Swissaid. Tales proyectos surgieron

\footnotetext{
${ }^{50}$ Ver los casos de María, la hermana de Moisés (Ex 15,20), Débora (Jc 4,4-5; 5,1-2); Ana, la madre de Samuel (1S 2,1-2); Hulda (2R 22,14-16); Ana (Lc 2,36); la esposa del profeta Isaías (Is 8,3); las hijas del apóstol Felipe (Hch 21,9); y muchas mujeres de las primeras comunidades cristianas (1Co,11).

${ }^{51}$ Alcántara, Entrevista, parte 4, 20 de septiembre de 2013, 5.

52 Idem, parte, 2, 9 de septiembre de 2013, 5.
} 
cuando Salvador, al llegar a pastorear en El Garzal, estudió las actividades económicas de los habitantes del corregimiento y su rentabilidad, basadas especialmente en cultivo del maíz. Concluyó que este cultivo no era suficientemente rentable como para generar suficientes excedentes que permitieran mejorar la calidad de vida de la población.

El cacao surgió como una alternativa consistente; por medio de Asproas se solicitaron semillas y financiación internacional para este cultivo, con muy buenos resultados. De esta manera, el cacao de El Garzal ha llegado a ser reconocido como uno de los mejores de Colombia. De igual forma, otros proyectos adjuntos se han generado, también con muy buenos resultados. Sin embargo, elementos cruciales, como la electrificación y el agua potable, no han sido posibles debido al conflicto por la propiedad de las tierras. Esto también ha impedido una mejora sustancial en la construcción de las viviendas, que en su mayoría todavía son de madera, pues los campesinos han dudado en invertir en algo que después tendrían que abandonar.

\section{Conclusión: la fe}

La fe se muestra en este proceso como la primera y gran causa motivadora de la resistencia mantenida por la comunidad de El Garzal a lo largo de más de quince años frente a las amenazas de despojo, desplazamiento e incluso exterminio. Asimismo, se presenta como sustento de un nuevo sentido identitario, que rompe con la "tradición" expuesta por las iglesias cristianas pentecostales en Colombia y América Latina.

El contexto ha permitido que representaciones y prácticas religiosas tradicionalmente orientadas hacia cierto "espiritualismo" y un claro quietismo social hayan sido resignificadas en un contexto de frontera y de amenaza a la supervivencia. Este hecho no es exclusivo de este caso, ya que puede encontrarse también en algunas comunidades de fe similares, en distintas regiones del país, que comparten con la de El Garzal su situación de marginamiento, abandono del Estado, dificultades económicas y violencia. ${ }^{53}$

Tales comunidades asumen de diferente manera la comprensión del mensaje evangélico y de su propia fe, de modo que se observa una naciente reorientación de

\footnotetext{
${ }^{53}$ Gracias al trabajo conjunto del Centro Nacional de Memoria Histórica y de la Iglesia Menonita se ha podido conocer la experiencia de por lo menos cuatro comunidades de fe que han vivido procesos de desplazamiento forzado y asesinatos por parte de distintos grupos armados, y que luego han sabido regresar, levantarse, reconstruirse y proyectarse, animados por su fe. Tales comunidades se encuentran ubicadas en Corinto (Cauca), Tierralta (Córdoba), Toribío (Cauca) y Macayepo (Bolívar).
} 
prácticas y representaciones religiosas, así como una visión distinta de la relación entre creyente-sociedad, creyente-economía y creyente-política. ${ }^{54}$

En palabras de Rafael Ávila, los sistemas religiosos tienen una capacidad, "una gestión moral para influenciar la opinión de personas y sociedades, y por su medio, sus prácticas sociales", claves para consolidar un proyecto o resistir a este. ${ }^{55}$ Una vez el proceso se pone en marcha, la conciencia religiosa brinda, a los actores, la capacidad de ir hasta el límite y vencer el miedo o los temores naturales, ya que -para los creyentes- lo espiritual está por encima de lo temporal, y cuando un actor social y religioso considera que la divinidad está de su parte, se siente incontenible.

Al hacerlo, "inevitablemente debe ocurrir una trasposición de códigos políticos a códigos religiosos, de manera que la gente pueda justificar y comprender lo que busca realizar". ${ }^{56} \mathrm{Tal}$ interacción genera imágenes culturales ("modelos culturales" los llama Houtart ${ }^{57}$ que median la lectura del mundo y construyen nuevas actitudes, disposiciones y predisposiciones que orientan el rumbo de los procesos de resistencia.

Se genera así una nueva interpretación de la fe, que es usada en clave de liberación y que asume rasgos antropológicos: Dios se revela a las comunidades humanas que creen en sí mismas, es decir, que poseen una práctica correcta, sociohistórica y trascendente de sus identidades personales, comunitarias y étnicas, y que las proyecta, con mayor o menor conciencia. ${ }^{58}$

Esta fe resiste desde la diversidad religiosa y política, en medio del terror de la guerra y la incertidumbre; es creativa a la hora de organizar a la comunidad; enfrenta al modelo económico dominante, es solidaria, celebra la vida y genera esperanza.

Es clara la articulación coherente entre la Biblia, la fe y el momento presente. La fe, por tanto, no es fruto exclusivo de un acto intelectual, sino también de un marco interpretativo (narraciones), de una "memoria" que permite comprender la vida diaria y los sucesos cotidianos en los que se juega la vida en comunidad. 59

Así, los procesos religiosos, sociales y políticos de comunidades de fe se apropian de la memoria del pasado para -en este caso- animar luchas de búsqueda de justicia

\footnotetext{
${ }^{54}$ Pereira, "Fronteras, mujeres desplazadas y espiritualidades", 5.

55 Ávila Penagos, "Modelo cultural y orden social”, 373.

${ }^{56}$ Plata Quezada, "Religión y movimiento social: la Cédula del común y la insurrección de los Comuneros. Nueva Granada (1781)", 504.

${ }^{57}$ Houtart y Lemercier, L'energie et la culture, 11-12; Houtart, El cambio social en América Latina.

${ }^{58}$ Seminario Construcción de Memoria desde Comunidades de Fe, Bogotá, CNHM, 28 de agosto de 2014, Apuntes de los autores.

${ }^{59}$ Hervieu-Léger, La religión, hilo de memoria.
} 
y paz. Aparecen entonces figuras que se homologan a la situación de la comunidad como "venía un pueblo a atacarlos y destruirlos" (narcotráfico, violencia), "el jefe de ellos que era el rey" (un liderazgo reconocido y afianzado), "convocó al pueblo" (participación activa de la comunidad). De esas mismas analogías derivan la seguridad del éxito en palabras como "yo les voy a dar triunfo".

Pero la fe también está basada en experiencias concretas, vividas de manera individual o comunitaria. Ya en otras oportunidades Dios había manifestado su protección y enviado signos concretos. Por ello, cuando la comunidad de El Garzal enfrenta la amenaza, no parte de la nada sino que su confianza está basada en hechos anteriores, en una experiencia previa.

Por otra parte, en la interpretación de la fe en sentido liberador juega un rol determinante la figura del líder religioso, que en países muy signados por la religión, como Colombia, adquiere importancia decisiva en la vida y suerte de una comunidad de fe. En el caso de Salvador, su formación particular y su propia experiencia han hecho de él un sujeto consciente políticamente y con gran sensibilidad social, todo lo cual incidió a la hora de interpretar los acontecimientos en clave de fe y actuar en consecuencia. Además su fortaleza y el apoyo estratégico brindado por instituciones externas le ayudaron a no decaer, y de esta forma, a impedir que la comunidad pastoreada decayera y cediera ante la presión.

Como prácticas religiosas en la base de la resistencia se encuentran la oración, la vigilia y el ayuno. De origen bíblico y realizadas desde los patriarcas hasta los apóstoles, pasando por Jesucristo, la vigilia, la penitencia y el ayuno se han utilizado como maneras a veces desesperadas pero a la vez profundas de comunicarse con Dios y pedirle -a veces exigirle- su intervención. Estas prácticas tienen también un significado sociopolítico cuando se utilizan para luchas de liberación o resistencia, que también tiene su base bíblica, en especial, en el Antiguo Testamento (Jdt 4,9-15; Est 4).

Así, tanto la comunidad de El Garzal como otras comunidades cristianas que se han enfrentado a los violentos y han experimentado situaciones límite, tienen en la oración, el ayuno y la vigilia el motor de su fe, que anima la resistencia y la génesis de procesos sociales y políticos. Y todas, a juicio de los resultados de las investigaciones, certifican la efectividad de sus resultados: ataques que no se producen, bombas que explotan sin hacer daño a nadie, temor sobrenatural que debilita y hace huir al agresor y al victimario, e incluso enfrentamientos con ejércitos de ángeles que defienden a los creyentes.

Las comunidades cristianas en resistencia como la de El Garzal generan, además, un tipo de ética progresista, que busca el respeto a los derechos humanos y el medio ambiente. Esta ética promueve el trabajo digno, la agricultura respetuosa del entorno, 
rechaza el dinero fácil, los cultivos ilícitos, premia el trabajo y el esfuerzo, y genera una economía solidaria y comunitaria. Esta ética, sin duda, puede constituirse en la base para la construcción de un nuevo proyecto político y de sociedad democrática.

A diferencia de otras víctimas del conflicto armado que quedan en total desamparo, las comunidades de fe tienen algo muy especial: su capacidad de aglutinarse de nuevo alrededor de un proyecto común, de reconstruir sobre las cenizas, como ha sucedido en otros casos similares al Garzal (Macayepo, Tierralta, Corinto y Toribío), de resistir pacíficamente. Estas comunidades, aunque han sido victimizadas y sufrieron agresiones, logran frenar el ciclo de violencia, incluído un proceso sanador, terapéutico, si se quiere. Permiten, además, ver al otro como un igual, pues la comunidad de fe, en este tipo de contextos, borra o disminuye las barreras de clase, etnia, género, pues todos son, a fin y cuentas, "hijos de Dios".

Esta capacidad de ver al otro como igual es un valor inapreciable, pues se convierte en elemento clave para confrontar a la guerra misma, cuya principal característica es precisamente obstruir dicha capacidad. $Y$ en ello se genera un encuentro con el proyecto democrático, porque el ejercicio de la ciudadanía democrática es, precisamente, la capacidad de ver en el otro a un igual. ${ }^{60}$ Además, la ciudadanía exige, para poder reconocer al otro, reconocerse a sí mismo en su dignidad; y las comunidades de fe generan dignidad en las personas, elemento básico para construir y reconstruir.

Así, el proceso de resistencia llevado a cabo por la comunidad de El Garzal ayuda a la construcción de Estado desde la base comunitaria:

...las comunidades y las personas que las conforman están pautando normas y claves de convivencia y gobernabilidad que trascienden a otros espacios públicos, convirtiéndose en referentes para la acción de otros y de sus sucesores. En estos casos las pautas de convivencia no son ajenas a la comunidad ni regladas distantemente por las instituciones formales del Estado. Esta dinámica invierte el conjunto de procedimientos por medio de los cuales se instauraron las pautas de convivencia en el país. Y son los propios actores comunitarios los que definen las estrategias de gobierno, de participación y gestión en función de las características que definen sus condiciones de vida. ${ }^{61}$

\footnotetext{
${ }^{60}$ María Emma Wills, en la apertura del Seminario Construcción de Memoria desde Comunidades de Fe, Bogotá, 27 de noviembre de 2014.

${ }^{61}$ Molina, "Resistencia comunitaria y transformación de conflictos", Atenea digital 6 (2004): 5-7. Disponible en: Redalyc, http://www.redalyc.org/articuloBasic.oa?id=53700637 (consultado el 11 de noviembre de 2014).
} 
Sin embargo, esta manera de orientar la fe cristiana no está exenta de controversias, tanto al interior de las mismas instituciones religiosas como fuera de ellas. Porque toda acción liberadora puede ser vista como peligrosa para el statu quo o para la tradición, sobre todo, en organizaciones ligadas al poder o acomodadas al sistema, que suelen tener una interpretación predominante de la fe en perspectiva individualista.

Por eso, la comunidad de El Garzal no solo ha tenido que confrontar a los violentos y a los agresores externos; su particular manera de obrar, para nada corriente en el interior de las iglesias cristianas evangélicas, también generó suspicacias y confrontaciones. Salvador cuenta que al comienzo debió enfrentar la oposición de varios pastores de su propia Iglesia, hasta llegar a estar a punto de ser destituido de su cargo de pastor. $^{62}$

Solo después de verse los resultados y de ser reconocido el proceso como ejemplo nacional e internacional, vino el reconocimiento por parte de la propia Iglesia Cuadrangular. Varios de sus dirigentes han solicitado a Salvador realizar en sus iglesias procesos de capacitación y formación comunitaria, que -se espera-generen procesos pedagógicos sobre cómo las iglesias cristianas (católicos incluidos) pueden contribuir a la construcción de una sociedad solidaria y democrática.

El ejemplo de El Garzal no solo ha cundido entre las iglesias evangélicas y cristianas; también ha influido a otras comunidades, en el ámbito regional y nacional, de manera que algunas comunidades vecinas -no necesariamente articuladas en torno de la fe- que han sufrido situaciones similares, han visto en el caso de El Garzal un ejemplo de cómo deben actuar, al recibir la convicción de ser sujetos de su propio destino.

\section{Fuentes y bibliografía}

\section{Entrevistas y talleres}

Alcántara, Salvador. Entrevista. Parte 1, 7 de septiembre de 2013 [audio digital]. . Entrevista. Parte 2, 9 de septiembre de 2013 [audio digital]. . Entrevista. Parte 3, 19 de septiembre de 2013 [audio digital]. . Entrevista. Parte 4, 20 de septiembre de 2013 [audio digital]. Alcántara, Salvador. "Predicación.” 14 de septiembre de 2014 [audio digital]. Alian, Nidia y Almaida Alcántara. Entrevista. 1º de marzo de 2014 [audio digital].

${ }^{62}$ Alcántara, Entrevista, parte 2, 9 de septiembre de 2013, 19. 
Castilla, Juan de Dios. Entrevista. 7 de febrero de 2014 [audio digital].

Esquivia, Ricardo. Entrevista. 27 de julio de 2013 [transcripción en procesador de textos].

Mendoza, Samuel, y Dubys Alcántara. Entrevista. 1º de marzo de 2014 [audio digital].

Neme, Jenny. Entrevista. 23 de agosto de 2013 [transcripción en procesador de textos].

Líderes de la comunidad de El Garzal. Entrevista. 14 de septiembre de 2014 [audio digital].

Taller de Construcción de Línea del Tiempo con la Comunidad de El Garzal. 28 de febrero de 2014 [video digital].

Taller de Construcción de Mapa de Memoria con la comunidad de El Garzal. 28 de febrero de 2014 [video digital].

Taller de Construcción de Memoria con la Comunidad de El Garzal. 28 de febrero de 2014 [audio digital].

\section{Referencias bibliográficas}

Ávila Penagos, Rafael. "Modelo cultural y orden social." En Religión y sociedad política en Nicaragua, por R. Ávila Penados, 345-381. Managua: Idehu-Upoli, 1998.

Beltran, William Mauricio y Rebeca Bartel (dirs.). "El Garzal: fe y resistencia." [Documental en DVD]. Bogotá: Universidad Nacional de Colombia, 2014.

Cepeda Van Houten, Alvaro. Clientelismo y fe: dinámicas del pentecostalismo en Colombia. Bogotá: Editorial Bonaventuriana, 2007.

Demera Vargas, Juan Diego. "Ciudad, migración y religión. Etnografía de los recursos identitarios y de la religiosidad del desplazado en Altos de Cazuca." Theologica Xaveriana 162 (2007): 303-320.

Equipos Cristianos de Acción por la Paz. "Presidente de Garzal, el reverendo Salvador Alcántara, es forzado a huir para salvar su vida." En CPT Colombia. Equipos Cristianos de Acción por la Paz. (20 de diciembre de 2011) (consultado el 17 de octubre de 2013).

. "Un líder desplazado retorna a su comunidad." CPT Colombia. Equipos Cristianos de Acción por la Paz. (16 de enero de 2014), http://www.ecapcolombia. org/2014/01/un-lider-desplazado-retorna-a-su-comunidad/\#.VCdSJfmSxqU (consultado en mayo de 2014). 
Figueroa, Helwar y William Elvis Plata. "Acteurs religieux pendant l'époque de La Violencia en Colombie, 1945-1965." En Mission et engagement politique apres 1945. Afrique, Amérique Latine, Europe, por C. Sappiay y O. Servais, 252-273. Paris: Editions Karthala, 2010.

Gafaro Martín, y Pablo Stucky. Construyendo la paz. Aprendizajes desde la base. El conflicto Colombiano y las iglesias santuarios de paz. Tres iglesias santuarios de paz de la costa caribe de Colombia presentan sus experiencias y aprendizajes. Bogotá: Centro Cristiano para Justicia, Paz y Acción Noviolenta, Justapaz LutheranWorldRelief, 2006.

Grupo de Memoria Histórica. ¡Basta ya!: Memorias de guerra y dignidad. Bogotá: Centro Nacional de Memoria Histórica, 2013.

Hernández Delgado, Esperanza. Intervenir antes de que anochezca. Mediaciones, intermediaciones y diplomacias noviolentas de base social en el conflicto armado colombiano. Bucaramanga: Universidad Autónoma de Bucaramanga, Instituto de Estudios Políticos, 2012.

Hervieu-Léger, Danielle. La religión, hilo de memoria. Barcelona: Herder, 2005.

Houtart, François. El cambio social en América Latina. Madrid: Editorial Senen Martín, 1964.

Houtart, François y Guy Lemercier. L'energie et la culture. Paris: L'Harmattan, 1990. Hurtatis Espinosa, Héctor Iván. "La Asociación Campesina del Valle del Río Cimitarra como mecanismo de resistencia política a los proyectos latifundistas en el Magdalena Medio (2006-2010).” Trabajo de grado en Ciencia Política, Universidad del Rosario, Facultad de Ciencia Política y Gobierno, Bogotá, 2012.

Lozano, Fabio. "Evangélicos y pobreza. Reflexiones a partir del estudio de la acción social de las iglesias evangélicas en Colombia." En: ¿El Reino de Dios es de este mundo?: el papel ambiguo de las religiones en la luch contra la pobreza, compilado por G. Zalpa y H.E. Offerdal, 253-274. Bogotá: Siglo del Hombre-CLACSO, 2008.

Mafla, Nelson Roberto. "Función de la religión en la vida de las víctimas del desplazamiento forzado en Colombia." Tesis doctoral, Universidad Complutense, Madrid, 2013.

Miller-Eshleman, Micah. "Salvador Alcántara." Bearing Witness. Stories Project (11 de octubre de 2014), http://www.martyrstories.org/salvador-alcantara-2/?lang=es (consultado el 15 de noviembre de 2014). 
Molina, Nelson. "Resistencia comunitaria y transformación de conflictos. Un análisis desde el conflicto político-armado colombiano." Atenea digital 6 (2004): 4. Disponible en: Redalyc, http://www.redalyc.org/articuloBasic.oa?id=53700637 (consultado el 11 de noviembre de 2014).

Molano, Alfredo. Molano, Alfredo. "Campesinos, narcos y humedales." El Espectador, Bogotá, 17 de diciembre de 2011, http://www.elespectador.com/noticias/ nacional/campesinos-narcos-y-humedales-articulo-317232 (consultado el 10 de octubre de 2014).

. “Caso El Garzal.” Diario El Espectador. Bogotá, 19 de agosto de 2012.

Paz, Felipe (director y productor). "Salvador" [Video-documental]. Bogotá: Centro Nacional de Memoria Histórica-USAID, 2014. Disponible en: https://vimeo. com/122791814 (consultado el 15 de marzo de 2015).

Pereira, Ana Mercedes. "Fronteras, mujeres desplazadas y espiritualidades." Pasos 146 (2009): 21-27.

Plata Quezada, William. "Religión y movimiento social: la Cédula del común y la insurrección de los Comuneros. Nueva Granada (1781).” Theologica Xaveriana 172 (2011): 473-508.

Red de Iniciativas y Comunidades de Paz. "La comunidad de El Garzal (sur de Bolívar) denuncia posible apropiación ilegal de tierras del Estado y una amenaza de desalojo para el 13 de diciembre." Notiagen (2011), http://www.pazdesdelabase. org/index.php?option=com_content\&view=article\&id=887:la-comunidad de-el-garzal-sur-de-bolivar-denuncia-posible-apropiacion-ilegal-de-tierras-delestado-y-una-amenaza-de-desalojo-para-el-13-de-diciembre\&catid=54:asproa s\&Itemid=99 (consultado el 11 de junio de 2014).

Restrepo, Gloria Inés. "Dinámicas e interacciones en los procesos de resistencia civil." Revista Colombiana de Sociología 27 (2006): 169-202.

Riaño, Pilar y María Emma Wills (coords.). Recordar y narrar. Herramientas para reconstruir memoria histórica. Bogotá: Comisión Nacional de Reparación y Reconciliación, 2009.

Román, Carlos Eduardo; Carlos Julio Rozo y Argemiro Vergara. Comunidades de fe en adversidad. Una narración de la tradición de fe en Medellin del Ariari (Meta). Bogotá: Pontificia Universidad Javeriana, Facultad de Teología, 2011.

Shantz, Pierre. "Inspecciones y oraciones." Oración.Resistencia.Comunidad. Un blog de Equipos Cristianos de Acción por la Paz (29 de junio de 2012), http:// 
ecapcolombia.wordpress.com/2012/06/29/inspecciones-y-oraciones/ (consultado el 7 de septiembre de 2013).

. "¿Por qué la victoria tiene que significar un paso más al desastre en lugar de la felicidad?" Equipos Cristianos de Acción por la Paz (17 de junio de 2013), http:// www.ecapcolombia.org/2013/06/por-que-la-victoria-tiene-que-significar-unpaso-mas-al-desastre-en-lugar-de-la-felicidad/2/\#.VG926vmG-So (consultado el 26 de agosto de 2014).

Sistiva, Diana. “Trauma, religión y cultura: los diversos roles de la religión en el afrontamiento de la violencia organizada en Colombia.” Tesis doctoral en Psicología, Université Victor Segalen Bordeaux 2, Université du Québec à Montréal, 2009.

Stucky, Pedro. Bases biblico-teológicas del quehacer de las iglesias en la construcción de la paz. Tres iglesias santuarios de paz de la costa caribe de Colombia presentan sus experiencias y aprendizajes. Bogotá: Centro Cristiano para Justicia, Paz y Acción Noviolenta, Justapaz - LutheranWorld Relief, 2006.

Summermatter, Stefania. "Un campesino sin tierra es como un pez fuera del agua." Swissinfo.ch (17 de septiembre de 2011), http://www.swissinfo.ch/spa/-uncampesino-sin-tierra-es-como-un-pez-fuera-del-agua-/31058248 (consultado en agosto de 2014).

SwissAid. "Au revoir ASPROAS: notre collaboration prend fin après 16 ans." Swissaid. Aider avec courage (2013), http://www.swissaid.ch/fr/asproas-fin-collaboration (consultado en septiembre de 2014).

Tejeiro Clemencia (ed.). El Pentecostalismo en Colombia. Prácticas religiosas, liderazgo y participación política. Bogotá: Universidad Nacional de Colombia, CES, 2010.

Thompson, Leslie. "Establishment and Growth of Protestantism in Colombia." Tesis doctoral en Educación, University of Wales, School of Education. Bangor, 2005. Disponible en: Prolades, http://www.prolades.com/cra/regions/sam/col/ thompson_thesis.pdf (consultado el 15 de marzo de 2014).

Tribunal Superior del Distrito Judicial de Bogotá. Sala de Justicia y Paz. "Sentencia contra Rodrigo Pérez Alzate." Bogotá, 30 de agosto de 2013.

Vega, Felipe. "Desplazamiento forzado: biopolítico de la invisibilidad." Theologica Xaveriana 149 (2004): 119-134.

Verdad Abierta. "Nos convertimos en una máquina de matar: Julián Bolívar." Verdad Abierta. Conflicto armado en Colombia (29 de octubre de 2009), www. 
verdadabierta.com/.../1903-qnos-convertimos-en-una-maquina-de-matarqjulian-bolivar (consultado el 26 de agosto de 2014).

Zalpa, Genaro y Hans Egil Offerdal (comps.) ¿El reino de Dios es de este mundo? El papel ambiguo de las religiones en la lucha contra la pobreza. Bogotá: Siglo del Hombre Editores, 2008. 